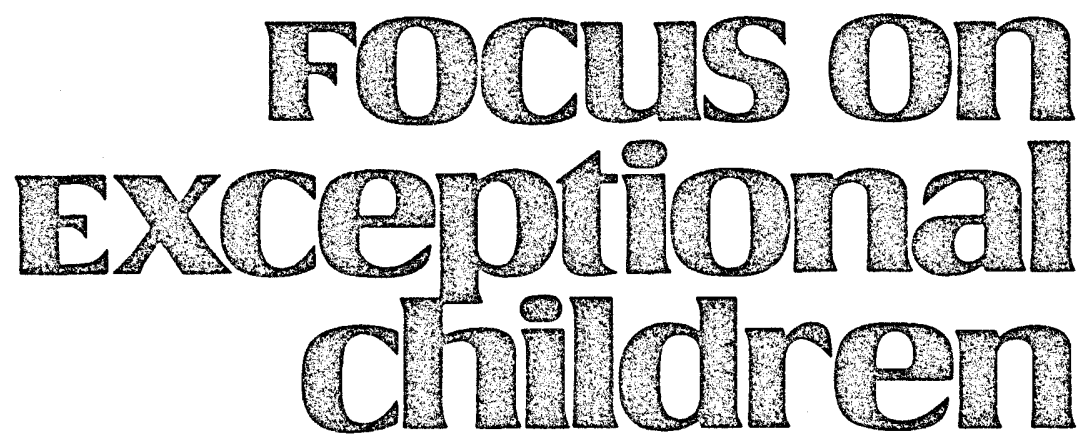

\title{
Transitions in Early Childhood Special Education: Issues and Procedures
}

\author{
Mark Wolery
}

Providing adequate early intervention programs requires consideration of many questions. These questions are related to the philosophy of the program, service delivery model, assessment of needs, and development of intervention plans. In addition, program leaders must ask, "How can we facilitate the transition of infants and preschoolers from one program to another?" This question, issues that surround it, and procedures for planning transitions are described in this article. Initially, the term transition and related terms are defined, and the relevant types of transitions that occur during early childhood are discussed. Then rationale for studying and planning transitions is explored, and particular transitions are discussed.

\section{DEFINITION AND TYPES OF TRANSITIONS}

In the past decade, considerable emphasis has been placed on facilitating transitions from school-based programs to adult service programs (Ianacone \& Stodden, 1987; Pueschel, 1988). Transition is defined as "passage from one state, stage, subject, or place to another ... a movement, a development, or evolution from one form, stage, or style to another (Webster's Ninth New Collegiate Dictionary, 1988, p. 1254). Will (1984) defined transitions as a process that is "a bridge between the security and structure offered by the present program and the opportunities and risks of a subsequent least restrictive environment" (p. 4). The procedures used to construct this bridge, known as transition practices, have been defined by Hutinger (1981) as "strategies and procedures that are planned and employed to insure the smooth placement and subsequent adjustment of the child as he or she moves from one program into another" (p. 8). Noonan and Kilgo (1987) maintain that these definitions indicate that transition is: (a) a longitudinal plan; (b) a goal of smooth/efficient movement from one program to the next; (c) a process including preparation, implementation, and follow up; and (d) a philosophy that movement to the next program implies movement to a program that is less restrictive than the previous program (p. 26).

Dr: Wolery is an Associate Professor, Department of Special Education, University of Kentucky. 
In addition to defining transitions, definition of related terms is necessary. In this article the term infant program refers to an intervention program serving infants and toddlers and their families who are eligible under the Education of the Handicapped Amendments of 1986 (PL 99-457). This designation is used regardless of the administrative agency responsible for providing those programs. Likewise, preschool program refers to an early intervention program serving children from 3 to 5 years of age who are eligible under PL 99-457, regardless of whether the services are provided directly by the local education agency (LEA) or through contracts with the LEA. Using Hutinger's (1981) lead, the program from which the infant/child is moving is referred to as the "sending" program, and the program to which the infant/child is moving is called the "receiving" program.

Using a broad conceptualization of transition, at least three types of transitions may occur in early childhood special education programs, and each deserves attention by early interventionists. The first type of transitions might be

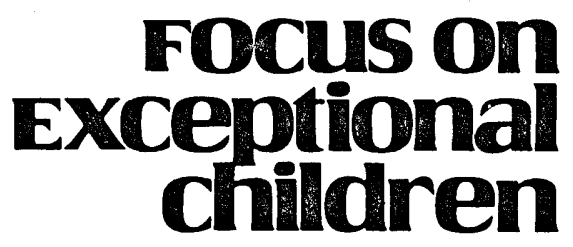

ISSN0015-511X

FOCUS ON EXCEPTIONAL CHILDREN (USPS 203-360) is published monthly except June, July, and August as a service to teachers, special educators, curriculum specialists, administrators, and those concerned with the special education of exceptional children. This publication is annotated and indexed by the ERIC Clearinghouse on Handicapped and Gifted Children for publication in the monthly Current Index to Journals in Education (CIJE) and the quarterly index, Exeptional Children Education Resources (ECER).. It is also available in microform from Xerox University Microfilms, Ann Arbor, MI. Subscription rates: Individual, \$27 per year, institutions, $\$ 36$ per year. Copyright (C) 1989, Love Publishing Company. All rights reserved. Reproduction in whole or part without written permission is prohibited. Printed in the United States of America. Second class postage is paid at Denver, Colorado. POSTMASTER: Send address changes to:

Love Publishing Company

Executive and Editorial Office

1777 South Bellaire Street

Denver, Colorado 80222

Telephone (303) 757-2579
Edward L. Meyen University of Kansas

Richard J. Whelan

University of Kansas Medical Center called developmental transitions. These are sequential transitions that are frequently age-based and are the type frequently thought of when discussing transitions. Developmental transitions include movement from extended hospitalization to home and infant programs, movement from infant programs to preschool programs, and movement from preschool programs to school-age programs. Developmental transitions also include movement from one class in a center-based program to another class in that program. Most infants and preschoolers with handicaps will experience developmental transitions.

The second type of transitions can be termed nondevelopmental transitions and occur within each age group. Usually they involve movement from one program to another that varies on the dimension of restrictiveness and possibly the extent of contact with typical peers. For example, a preschooler might move from a program that enrolls only preschoolers with handicaps to a less restrictive preschool program designed primarily for typical children. Not all infants and preschoolers experience nondevelopmental transitions; however, when they occur, planning is necessary.

The third type of transition can be called within-class transitions. These transitions occur in center-based programs and focus on movement from one activity to another. This article deals with developmental and nondevelopmental transitions; within-class transitions are not addressed. Other sources describe designing schedules for preschool classrooms (Bailey \& Wolery, 1984; Carta, Sainato, \& Greenwood, 1988), reducing within-class transition times (Sainato, Strain, Lefebvre, \& Rapp, 1987; Goetz, Ayala, Hatfield, Marshall, \& Etzel, 1983), and teaching during within-class transitions (Wolery, Doyle, Gast, Ault, \& Lichtenberg, 1989).

\section{RATIONALE FOR STUDYING AND PLANNING TRANSITIONS}

At least four rationales can be identified for studying and planning transitions:

1. To ensure continuity of services (Flynn \& McCollum, in press; Noonan \& Kilgo, 1987)

2. To minimize disruptions to the family system by facilitating adaptation to change (Diamond, Spiegel-McGill, \& Hanrahan, 1988; Fowler, Chandler, Johnson, \& Stella, 1988) 
3. To ensure that children are prepared to function in the receiving program (Fowler, 1982; Noonan \& Kilgo, 1987)

4. To fulfill, in some cases, the legal requirements of P.L. 99-457.

The relative emphasis of each of these rationales varies for different types of transitions.

Continuity of services refers to the extent to which the services needed and provided in the sending program are continued in the receiving program. Continuity has two primary elements: (a) the needed services, and (b) the provided services. Almost by definition, transitions imply changes in needs. If no change in needs exists, a transition may not be necessary. Because different programs have different missions, they undoubtedly are designed to meet different needs, or at least to place different emphasis on given needs.

For example, the primary mission of an intensive care nursery is to ensure infants' survivability and promote health. But the primary mission of most infant programs is to promote adequate parent-infant interactions, facilitate the infant's development and independence, and enhance the family's capability to promote the infant's development and meet individually defined goals within the family. Thus, transition from intensive care nurseries to a communitybased infant programs may constitute a dramatic shift in which needs are addressed.

Different needs or different emphases on continuing needs implies that different services will be provided. These shifts may result in some needs not being addressed or being given less emphasis in the receiving program. Thus, it is imperative that the needs and services that were given priority in the sending program not be ignored in the receiving program. For example, attention to the infant's survivability and health should continue in the infant program after his or her leaving the intensive care nursery.

In relation to ensuring continuity, it is important to focus on the perception of needs as well as the reality of need. For example, an infant may leave the hospital quite healthy, but because of the history of extended hospitalization and life-threatening events, the family may continue to perceive this as the primary focus of intervention rather than recognize the need to provide a responsive, development-producing environment. Thus, to ensure continuity of services, the transition from one program to the other should be planned.

Transitions cause change in the family system that may be related to increase in reported stress (Fowler, et al.,
1988). Diamond et al. (1988) suggest that Brohfenbrenner's (1986) ecological-developmental model is useful in conceptualizing changes in the family system as a result of a transition. This model adopts a systems perspective of the family, meaning that each member and the unit as a whole have needs, roles, and functions (Dunst, 1985; Dunst, Trivette, \& Deal, 1988; Simeonsson, 1988b). The infant/child and family are seen as functioning in several environments called microsystems (e.g., home environment, program environment, community environments such as church or neighborhood, support systems such as medical or respite programs). These microsystems, which are related to and influence one another, constitute the mesosystem. Events that occur in one microsystem can influence performance in another; therefore, changes such as transition from one microsystem to another can influence the entire mesosystem.

A systems view of families also assumes that it changes with time; families progress through a sequence of events or stages (Simeonsson, 1988b). These events, called critical events, have been divided into two categories: normative events and non-normative events (Bailey, 1988). Normative events include getting married, having children, rearing children during early childhood, providing independence during adolescence, and adapting to life as children leave home. Non-normative events include things such as job loss, divorce, death of a family member, and serious illness. The presence in the family of an infant or child with handicaps also influences development of the family.

Bailey (1988b) reviewed information from a number of authors who identified stressful events related to rearing a child with handicaps; these are summarized in Table 1. As noted in this listing of critical events, each of these authors viewed entry into public school programs and program transitions as stressful events in the lives of families (Hanline, 1988). This reported stress may occur for many reasons. For example, the sending and receiving programs may differ in terms of location of services, schedule, transportation system, staff members involved, manner and frequency with which communication with families occurs, contact with social support such as other families, cost of services, expectations for family participation, and many others. Further, the receiving program may hold many unknowns for the family. Thus, to minimize disruption to the family system and to minimize the stress involved in the potential changes, transitions should be planned carefully.

In addition to ensuring continuity of services and minimizing disruptions to the family system, transitions should 


\section{TABLE 1}

Critical Events Related

\section{To Rearing a Handicapped Family Member}

\section{Author(s)}

MacKeith (1973)

Bray, Coleman, \&

Bracken (1981)

Events causing stress for family in parenting handicapped family member

Wickler (1981)

Critical events that are stressful for families
Specific Events of Concern

Family becomes aware that child is handicapped

Family must decide on educational placement Handicapped family member leaves school as young adult

Family realizes parents can no longer care for handicapped family member

Family learns of diagnosis

Family must deal with medical management

Family receives incomplete or inaccurate diagnostic information

Family deals with prognosis for handicapped family member

Family must decide on educational placement and services

Age child should have begun to walk Age child should have begun to talk Beginning public school

Onset of puberty

Child's 21st birthday

Initial and subsequent diagnoses

Younger typical child equals or exceeds abilities of handicapped family member

Consideration of placements outside of home

Excessive inappropriate behaviors, seizures, health problems

Consideration of guardianship and long-term care

Family recently learned of diagnosis Typical sibling is matching or beginning to exceed abilities of handicapped child

Program transition will occur in next few months

Medical procedure (e.g., operation) will occur in next few months

Child reached age of walking but is not

Child reached age of independent feeding but is not

Child reached age of talking but is not

Child reached age of being toilet trained but is not 
be planned to ensure that-children can perform the skills needed in the receiving program (Fowler, 1982). Because one goal of early intervention is to prepare infants and preschoolers to function in current and future environments, some of the instructional activities should be designed to prepare infants and preschoolers for the next most probable placement (Vincent et al., 1980). The intent of these activities is to promote maintenance and generalization of skills acquired in the sending program, to facilitate performance of idiosyncratic skills needed in the next program, to ensure that the child's behavior falls within the norm of children in the receiving program, and to identify adaptations and supports needed in the receiving program. Thus, to ensure that infants and children are ready for the next placement, careful planning of the transition is necessary.

Finally, transitions should be planned and studied because this type of planning is required by PL 99-457. The Individualized Family Service Plan (IFSP) must include a statement of the infant's present levels of functioning, statement of family needs and strengths, statement of outcomes, statement of services needed, projected dates of services, name of case manager, and "steps to be taken supporting the transition of the handicapped toddler to services provided under part B to the extent that such services are considered appropriate" (sec. 677, p. 6).

Thus, transition planning is a requirement of the IFSP process for toddlers who are leaving infant programs. In addition, one of the primary provisions of The Education for All Handicapped Children Act (PL 94-142) is that children be educated in the least restrictive appropriate environment. Thus, when children move from a more restrictive to a less restrictive placement, planning may be necessary.

\section{TRANSITION ISSUES AND PROCEDURES}

The transition from hospital neonatal intensive care units (NICU) to home and infant programs is described separately from other developmental and nondevelopmental transitions because of its uniqueness. Following this discussion, issues and procedures related to other transitions are addressed.

\section{Facilitating Transitions from NICU To Home and Infant Programs}

Not all infants with handicaps experience extended hospitalizations in a NICU, and not all infants who have extended hospitalizations will need infant intervention pro- grams. Many infants with handicaps, however, will spend from a few days to several weeks or months in an NICU. Transition from the NICU to home and infant programs should begin prior to the discharge of the infant from the hospital (Lang, Behle, \& Ballard, 1988). Communication with the family concerning the infant's status, progress, and prognosis is important.

In addition, parents should be encouraged and allowed to visit the infant frequently and at different times of the day. These visits can assist the family in becoming acquainted with the infant, the infant's response patterns, and the use of specialized treatments (Lang et al., 1988). Actual discharge from the hospital requires planning several issues including assessment of the (a) medical and developmental status of the infant, (b) needs and strengths of the family, (c) home environment, and (d) resources in the community (Katz, Pokorni, \& Long, 1988).

\section{Medical and Developmental Status}

The neonatologist and nursing staff are responsible for monitoring and assessing the infant's medical status to identify when transition to the home is warranted (Katz et al., 1988). In addition to ongoing monitoring, these professionals should ensure that all appropriate information and medical procedures needed prior to discharge are accomplished, specialized screening is completed (e.g., of sensory functioning), and a thorough discharge examination is executed (Lang et al., 1988). The medical status also should include assessment of "the level of respiratory support that the infant needs; the feeding method and rate of weight gain; the infant's autonomic regulation including respiration, heart rate and body temperature, and medical needs" (Katz et al., 1988, p. 43).

These assessments assist in determining when discharge is appropriate, what growth patterns are expected, and what equipment and assistance families will need in the home. Assessment of the developmental status will assist the NICU staff in determining whether support from an infant intervention program is necessary (Katz et al., 1988).

\section{Family Needs and Strengths}

When planning the transition from the NICU to the home, family needs and strengths should be assessed and considered. As noted, families ideally would visit the infant frequently during the hospitalization. In addition, attendance in parent support groups may assist the family in adapting to having an infant with handicaps (Lang et al., 1988). 
Assessment of family needs in terms of transition to the home should involve several areas. Family members' understanding of the infant's condition, medical status, prognosis, and their ability to explain this information to others are important issues (Bailey, 1988b). The family's willingness to care for the infant at home should be assessed through ongoing interviews and contacts during the hospitalization. Once families have decided to care for the child at home, NICU staff members must assess their knowledge and competence in providing routine care for the child. Prior to discharge, the family should be competent in bathing, feeding, diapering, and handling the infant (Harrison, 1983; Katz et al., 1988).

Further, the ability of families to provide specialized care and detect problems should be assessed (Harrison, 1983; Katz et al., 1988). To assist in assessment, several checklists have been developed. Katz et al. (1988) present a checklist to assess caregivers' competence with infants who have been tracheostomized or are ventilator assisted. It includes documentation of competence in (a) assessing breathing and other signs and symptoms of distress; (b) implementing procedures such as suctioning, trach care, and emergency care (e.g., CPR); (c) using, checking, and caring for specialized equipment such as Apnea monitors, ventilators, humidity systems, suction machines, and trach collars; (d) administering medications; and (e) documenting activity levels, respiratory distress, and nursing procedures. This checklist also includes a section for assessing individualized skills families may need.

Platzker et al. (1988) also present guidelines and lists of equipment related to home care of infants with chronic lung diseases. This includes a checklist for home care, description of medications, listing of equipment for infants with chronic lung disease, instructions for bronchodilator aerosol treatments, equipment needed for infants with tracheostomy, criteria for discharge of ventilator-assisted infant, and a listing of equipment needed for the infant. Howell (1988) presents descriptions of supplies and procedures for ostomy care for infants and young children. Lang et al. (1988) and Katz et al. (1988) recommend that the family stay overnight at the NICU to ensure that they are acquainted with the procedures for providing 24-hour care for the infant.

Assessment of family needs in other areas is also important. Katz et al. (1988) present a 43-item checklist for assessing home care needs, focusing on a number of relevant areas. Examples include response to emergencies (who to call, procedures for getting the child out of the house in the case of fire), availability of respite or alternative care- giving, training of alternative caregivers, availability of adequate transportation, identification of support personnel (e.g., pediatrician, nursing services), need for specialized therapists (e.g., occupational therapy, physical therapy), use of equipment, need for social services, and child care supplies (e.g., diapers, clothing). A number of scales and checklists that assess family needs but are not designed specifically for hospital-to-home transitions also are available (cf. Bailey \& Simeonsson, 1988; Dunst et al., 1988; Seligman \& Darling, 1989).

Finally, as the transition is planned, parents should be encouraged to ask questions related to taking the infant home. During the final discharge meeting, opportunities should be afforded parents to ask questions (Lang et al., 1988). Harrison (1983) lists 20 questions that families should ask of the NICU staff. These questions deal with organization of the home, feeding, sleeping patterns, immunizations, response to crying, the infant's current sensory status, and many others. Interventionists who will be serving the infant in the program also should assist parents in asking questions.

\section{Home Environment}

Assessment of the home environment should address two major areas: adequacy of the physical characteristics of the home, and adequacy of the home in promoting the infant/child's development. In the transition from the NICU to the home, physical characteristics are of primary importance. This assessment should identify the need to adapt the physical environment, whether space is adequate, whether the electrical supply allows for medical equipment, and access to telephone and alarms for smoke and potential power failures. Katz et al. (1988) present a checklist for evaluating the physical facilities of a home. Families should be informed of and assisted in making the necessary adaptations. Simeonsson (1988a) presents information on assessing adequacy of the home in facilitating the infant's development. This assessment and resulting intervention should be part of the infant intervention program.

\section{Community Resources}

Identification and assessment of the needed community resources are important to the hospital-to-home transition plan. During the hospitalization, the community pediatrician or family physician must be notified and informed of the infant's condition, progress, care, and medical needs 
(Lang et al., 1988). If possible, these physicians should participate in the discharge meeting; however, if they are not present, the NICU staff should directly contact them soon after discharge (Lang et al., 1988).

The discharge should not signal an end to communication between the NICU staff and the family. Families should be encouraged to contact the NICU if they need certain information or face new problems related to the infant's medical care. Likewise, follow-up telephone contacts or home visits from the NICU staff can ease the transition (Katz et al., 1988; Lang et al., 1988). These contacts can ensure that the family has been linked to needed resources.

Other resources the family may need, such as social services and intervention services, should be identified, and contact with those programs should occur prior to discharge. Ideally, families would be encouraged to avail themselves of the informal as well as formal support systems (Dunst et al., 1988). Informal support may come from the extended family members, church, neighbors, and other individuals. A number of scales and interview formats exist for identifying needed resources (cf. Bailey \& Simeonsson, 1988; Dunst et al., 1988). Still, referral to and contact with an infant intervention program are necessary to ensure that the family is not lost to the established service system (Flynn \& McCullom, in press).

In sum, transition from the NICU requires attention to a number of areas including the infant's medical and developmental status, needs of the family, adequacy of the home environment, and identification and availability of community resources. Much of the preparation for transition activities should focus on (a) the family's ability to care for the infant in the home, and (b) the linkage with resources (formal and informal) that will ensure continued development of the infant. Although much of this will be conducted by social workers, nurses, or others in the NICU, the infant intervention program staff also can play a role in identifying community services and supporting the family as they bring the child home.

\section{Other Developmental and Nondevelopmental Transitions}

Both developmental transitions (e.g., from an infant program to a preschool program and from preschool programs to school-age programs) and non-developmental transitions (from one infant program to another and from one preschool program to another) are addressed in this section.
Smooth, systematic transitions have at least four dimensions: (a) assessment of, and attention to, the needs of both the infant/child and the family; (b) open communication and information exchange between family members and staff members of the sending and receiving programs; (c) joint decision making between professionals and families; and (d) communication and information exchange between the personnel of the sending and receiving programs (Hains, Fowler, \& Chandler, 1988; Johnson, Chandler, Kerns, \& Fowler, 1986). The issues and procedures for implementing transitions are discussed in the following section. This section is organized by family, child, and interagency issues and procedures.

\section{Family Issues and Procedures}

The general goals for family participation in transitions are to ensure smooth movement of the child and family to the receiving program and to reduce family stress and disruption during the transition. In accomplishing this, the staff of the sending program in collaboration with the family should (a) identify and address parents' information and skill needs related specifically to transitions, (b) establish parents' roles and responsibilities during the transition, (c) determine and deal with parents' concerns and fears about transitions, and (d) establish appropriate communication between parents and relevant professionals in the sending and receiving programs (Hains et al., 1988; Hanline \& Knowlton, 1988).

As noted earlier, families should be assessed to identify their general needs related to enhancing the infant/child's development (Bailey \& Simeonsson, 1988; Dunst et al., 1988). Although this is required for parents of infants and toddlers, the intent of PL 99-457 (as specified in the Congressional Report on the act, Report 99-860, Education of the Handicapped Act Amendments of 1986, p. 20) is that it applies to the parents of preschoolers as well. Thus, infant and preschool programs should be continuously engaged in assessing and meeting the needs of families. Part of that assessment and intervention should focus on transition planning, including assessment of their needs for information, skills, and support.

Family information needs may include (a) parent and child rights and due process procedures; (b) referral and assessment procedures; (c) eligibility criteria including criteria for related services; (d) roles of parents and professionals during transition; (e) procedures related to IEP development, parents' roles and input into the IEP process, and the manner in which the IEP meeting will be conduct- 
ed; (f) placement options including the curriculum, teaching practices, opportunities for interactions with typical children, procedures for observing each program, procedures for evaluating the adequacy of those programs, expectations for parents, and teacher and therapist experience in each option; $(\mathrm{g})$ procedures for facilitating their infant/child's transition; (h) strategies for providing input and influencing transition decisions, and (i) community services that may be available. Clearly, not all parents will need information in each of these areas, but many parents will. Procedures for assessing these information needs frequently involve interviews and program-developed checklists.

Fowler et al. (1988) described a two-step interview process in which parents are interviewed in the fall of their infant/child's final year in the program and again in the spring of that year. The first interview focuses on "general transition information, sources of information regarding new programs, the parents' participation level, and sources of information on their child's progress" (Fowler et al., 1988, p. 210). Each of these areas has 7 to 13 items, rated from "not applicable" to "very important." Parents then are asked to rank the three most important items, and these are considered priorities in planning for the transition. Several open-ended questions are also included to stimulate communication and information exchange about transition. The second interview deals with choosing the best program and included items focused on:

\footnotetext{
... general description of the receiving (new) programs, ways to obtain information about the program, the parent's participation in making decisions about the new program, specific features of the receiving programs, a description of teacher characteristics, a description of classroom characteristics, a description of other children in the classroom, and criteria for selecting the receiving program. (Fowler et al., 1988, p. 210)
}

Each of these areas contained a number of items, and three open-ended items. Based on the results, parents were given a list that summarized the information they had rated as most important. They were encouraged to use this list in their contacts with potential receiving programs. This twostep interview process facilitated discussions of information about transitions, allowed some parents to add transition goals to the child's IEP, and assisted them in reviewing potential receiving programs.

Hanline and Knowlton (1988) also present a parent transition preparation checklist. It includes 12 items that can be used as an initial assessment of parents' preparedness for transition. After parents complete the checklist, it can be reviewed with a professional and specific information needs can be identified. Winton, Turnbull, and Blacher (1984) suggest that parents consider what various programs can provide for them and for their child. Variables they suggest that parents use to evaluate programs' provisions for parents include the cost, convenience, availability of day care services, amount of contact with other parents, and several others. In regard to what programs provide for children, they suggest evaluating whether the program promotes independence, helps the child feel good about himself or herself, facilitates children getting along with one another, and other issues.

To meet information needs, a number of strategies can be applied. Many programs have developed manuals designed specifically for parents in transition (see Hanline \& Knowlton, 1988; Noonan \& Stodden, 1986). Group meetings frequently are used; these include presentations by sending and receiving program staff members, videotapes of potential programs, group discussions, and question-and-answer sessions (Hanline \& Knowlton, 1988; Noonan \& Kilgo, 1987). Individual conversations with staff members from sending and receiving programs comprise another major source of information. Observation of the potential options and discussion with persons in those programs also are rich sources of information. Conversations with parents who have experienced transition and whose children are in the receiving programs offer a viable means of providing information to parents. A number of published and commercially available sources also exist; examples are presented in Table 2.

A variety of parent skill needs also may be identified and addressed. These include skills in teaching their infants/children behaviors needed in the receiving programs, decision-making strategies, and strategies for participating in IEP meetings. These probably are best assessed through direct observation and interviews. A well established method for teaching parents to teach their children involves describing the teaching procedure, demonstrating it for parents, observing the parents use the procedure, and providing them with feedback. Role playing and didactic instruction can be used for teaching decision making and IEP participation strategies.

For assessing needs for support, a number of scales exist (Bailey \& Simeonsson, 1988; Dunst et al., 1988). Moreover, program personnel should assume that most parents will need some social support during transitions. As shown in Table 1, parents frequently report that school entry or program transitions are stressful events. Use of the Critical Events Checklist (Bailey et al., 1986) allows program per- 
TABLE 2

\section{Commercially Available Parent Resources in Transition}

\section{Title}

An Education Handbook for Parents of Handicapped Children

Children's Psychological Testing: A Guide

Getting Your Child Ready for School

Just How Special Should a Preschool Be?

One Miracle at a Time: How to Get Help for Your Disabled Child

P.L. 94-142, Section 504, and P.L. 99-457: Understanding What They Are and Are Not

Related Services for Handicapped Children

Selecting a Preschool: A Guide for Parents of Handicapped Children

Some Practical Suggestions for the IEP

Unraveling the Special Education Maze: An Action Guide for Parents
Author

S.I. Mopsik \& J.A. Agard

D.L. Wodrich

L. Murphy \& S.D. Corte

P. Winton \& A. Turnbull

I. Dickman with S. Gordon

J. Ballard, B. Ramirez, \&

K. Zantal-Wiener

M.E. Esterson \& L.F. Bluth

P.J. Winton, A.P. Turnbull,

\& J. Blacher

K. Marafino

B.C. Cutler
Source/Publisher

Brookline Books, Cambridge, MA

Paul Brookes, Baltimore, MD

Special Parent-Special Child

Sept./Oct., 1985

Ways, Jan., 1986

Simon \& Shuster, New York, NY

Council for Exceptional Children, Reston, VA

College-Hill Press, Boston, MA

Pro-Ed, Austin, TX

Down Syndrome News, Nov., 1986

Research Press, Champaign, IL

From M.F. Hanline \& A. Knowlton, 1988, A collaborative model for providing support to parents during their child's transition from infant intervention to preschool special education public school programs, Journal of the Division for Early Childhood, 12, 121. Reprinted by permission.

sonnel to determine whether other stressful events are occurring simultaneously with transition. If so, the need for social support may be increased. In meeting social support needs, programs frequently opt for linking parents with other parents, providing them with professionals to contact about the transition process, and checking frequently on progress of the transition. As Dunst et al. (1988) indicate, however, use of existing support systems such as extended family members and neighbors is advisable.

A number of roles have been suggested for parents during transitions. Parents can serve as teachers, information providers, decision makers, advocates, transition coordinators (Hains et al., 1988; Noonan \& Kilgo, 1987).

As teachers, they would instruct their infant or child on skills that will increase the probability of success in the receiving programs. This may consist of teaching new skills that are needed, or assisting in establishing generalization of skills taught by others. In home-based or clinic/parent-consultation models, parents may have to assume a more active role as teacher in the transition process than parents whose infants/children are being served in center-based programs.

As information providers, parents supply information to transition planners about the infant's/child's skills and needs, effective instructional strategies, family needs related to transition, and other relevant information (Diamond et al., 1988). Also, as information providers they can participate in meetings related to the transition. 
As decision makers, parents may be asked to participate in deciding which placement best fits their infant or child, what behaviors and skills should be taught to him or her, what services the infant or child needs, what services other family members need during transition and from the receiving program, and when transition should occur.

As advocates, they must understand their rights and the rights of their children, ensure that due process procedures are implemented, identify instances when the best interests of their child and the family are not being met, and initiate appropriate action when their child is not being served appropriately. Also, as advocates, they can provide their support for programs and services, assist other parents in obtaining appropriate services, and lobby local, state, and national government officials for services for individuals with handicaps and their families.

As transition coordinators for their infant/child, parents assume the responsibilities for initial transition planning, implementing actual transition events, and providing follow-up information on the transition (Noonan \& Kilgo, 1987). Noonan and Kilgo provide three rationales for parents serving as transition coordinators. First, many parents will face several transitions during the life of their child. Thus, learning how to negotiate transitions smoothly may empower them to be more independent of professionals and deal with less than ideal situations where transitions are needed. Second, as members of teams and as the transition coordinator, parents are in a powerful position to advocate for the services and placements that are most appropriate for their offspring. Third, assuming the role of transition coordinator provides parents with more control of the process, which in turn may reduce the stress related to transition.

Smooth, successful transitions probably are most likely when parents serve multiple roles. Nevertheless, program personnel must recognize that not all parents can or desire to serve multiple roles in the transition process. Assuming particular roles probably is predicated on having the skills to function adequately in those roles. For example, parents who do not have good teaching skills will need to learn those skills before their efforts in the teacher role will benefit the child during transitions. Similarly, parents will need certain information before they can adequately serve some roles. Making decisions about services and placement options requires information about what is needed and what is available. Serving as an advocate for their child requires information about their rights and how to exercise those rights. Serving as a transition coordinator requires knowledge of the transition process, available options, procedures related to transition, and many other issues. It also requires skill in soliciting, analyzing, and acting on information. Finally, serving as a transition coordinator requires considerable time during the day to devote to the transition process.

To expect that all parents will have the skills, resources, and desire to serve as the transition coordinators for their children is undoubtedly unrealistic. Therefore, program personnel must engage in helping behaviors that promote as much independence as possible on the part of parents and at the same time provide them with the support they need to accomplish the roles they have chosen (see Dunst et al., 1988 , for characteristics of helping behaviors).

Clearly, some parents frequently fear the transition process or have important concerns about it. Consider the following statements by parents:

- "I saw making the transition to a preschool program in the school district as an extremely traumatic experience, second only to learning of Amy's diagnosis." (Hanline \& Knowlton, 1988, p. 116)

- "Getting on the bus for the first time was the biggest shock." (Johnson et al., 1986, p. 15)

- "I was scared to have him go to public school. I worry about him a lot ... If I had it my way, I'd never send him to school." (Johnson et al., 1986, p. 15)

These comments and the unpublished comments of many other parents indicate that transition from one program to the next is filled with uncertainty. Five statements about these fears and concerns are pertinent. First, being fearful or having concerns about the transition process is a realistic emotion. Many parents of typical children can recall their uneasiness about their child's first days at school. Second, the intensity and amount of fear parents experienced varies from family to family and from time to time. As a result, program personnel should provide families with frequent opportunities to express their concerns. Assessment of fears and concerns can occur through formal and informal interviews (Johnson et al., 1986) and perhaps through scales and checklists. Third, failure to identify and address fears and concerns may interfere with the transition process and may increase transition-related stress for families. Fourth, some fears and concerns may require ongoing monitoring. In many cases, fears and concerns may originate from lack of information, but contact with the receiving program and provision of information may cause the fears or concerns to 
diminish. In other cases, however, the fears and concerns may be less easily dispelled. For example, a family may fear that a child's educational needs will not be appropriately addressed in a particular kindergarten class. In such cases, monitoring the appropriateness of that class should occur after the child is enrolled. If the child's needs are not met, then changes in the operation of the class or a transition to another more appropriate placement is warranted.

Fifth, several standard procedures exist for dealing with many fears and concerns. These include having a clearly defined transition process (cf. Diamond et al., 1988; Hanline \& Knowlton, 1988); providing needed information (Hains et al., 1988; Hanline, 1988); providing needed family services (Hanline, 1988); providing informal, personal, and frequent contact and communication between families and the staff of the sending and receiving programs (Diamond et al., 1988); allowing parents to visit potential placement sites and teachers prior to transition (Johnson et al., 1986); and identifying one person in the receiving program who can deal with questions and concerns about transition (Hanline, 1988).

To increase the smoothness of transitions and reduce family stress, communication between the family and sending and receiving programs must be established (Diamond et al., 1988). The communication must occur at several different levels. First, all programs providing services to families should have some system for formally and informally communicating with families (cf. Winton, 1988). If frequent communication exists between the program and families, communication related to transitions is simply an extension of previous exchanges. In addition to communication between the sending program and families, communication has to be established between the receiving program and families. Parents appear to prefer to have one person from the receiving program with whom to communicate (Hanline, 1988). This person should be knowledgeable about the transition process, placement options, and availability of related services. In large systems this may be unrealistic, but individuals to contact clearly should be identified to parents. In many cases, someone in the administration of programs can serve that role. But, once a placement has been identified, the parents should have contact and communication with the direct service staff.

"The most effective way to enhance communication and interrelationships between settings is by providing opportunities for frequent, personal, and informal contact between these settings" (Diamond et al., 1988, p. 246). These contacts may include having the receiving program provide information about available services directly to parents well before the transition, inviting parents to social events at the receiving program in the months preceding the actual transition, allowing families to visit the receiving program and observe the program in operation, encouraging visits by the receiving staff to the sending program or the family's home, and allowing visits by the child and parent to the receiving program.

In summary, meeting the goal of a smooth, unstressful transition for families requires attention to several issues. Their information and service needs must be assessed and addressed. The various roles parents may play in the transition should be described to parents, and they should be supported in the roles they assume. Parents should be given opportunities to express their fears and concerns about the transition, and those fears and concerns should be addressed. Finally, communication between the sending and receiving program and the parents should be established and monitored.

\section{Child Issues and Procedures}

The goals of transition for infants and children are to provide them with a program that meets their needs more effectively and efficiently and to minimize the adjustment difficulties during transition. To accomplish these goals, the sending program must (a) define their exit criteria, (b) determine the infant's/child's current abilities and needs, (c) identify the skills and performance levels needed in potential receiving programs, (d) develop and implement a transition plan that maximizes the infant's/child's probability for success in the receiving program, and (e) implement follow-up procedures to determine whether the transition was successful and to identify and correct problems that arise.

Transition implicitly suggests that the sending program has met its objectives with the child or that the program can no longer adequately meet the child's needs. Recent investigations suggest, however, that this frequently is not the case (Thurlow, Lehr, \& Ysseldyke, 1987; Thurlow, Ysseldyke, \& Weiss, 1988). In reality, children usually leave programs because of their age.

Two disadvantages exist when exit decisions are based on age. First, children who are ready to exit from programs frequently are not allowed to leave them; second, children are moved to the next program without adequate preparation (Thurlow et al., 1988). To solve these difficulties, programs should allow for determination of whether their exit criteria are based on age only, progress only, or some combination of age and progress. They also should have provi- 
sions for assessing a variety of alternative placements and for modifying those programs to ensure that adequate services are provided to program graduates. Parents should be involved in exit/transition decisions, and timelines for determining progress should be defined and implemented (Thurlow et al., 1988).

Transition procedures, if based on age alone or on some combination with progress, should involve adequate assessment of the infant or child. This should include an interdisciplinary assessment and should address all relevant developmental domains and therapy needs. Conducting curriculum-based assessments involves the use of direct testing, direct observation, and interviews with relevant persons (Bailey \& Wolery, 1989). This information should be passed on to the receiving program.

In addition to an adequate curriculum-based assessment, the student should be assessed to identify the skills and performance levels needed in potential receiving programs. Developmental assessments usually do not provide this information. It must come from the demands of the receiving program (Noonan \& Kilgo, 1987) and can be obtained by conducting ecological inventories of those programs.

The steps for conducting ecological inventories are: (a) identify curricular domains needed by the child, (b) identify and survey the receiving programs, (c) divide the receiving program into subenvironments, (d) identify all relevant activities and routines used in each subenvironment, (e) identify the specific skills needed to perform the relevant activities and routines, and (f) assess the child against the skills needed in the activities and routines (Brown et al., 1979; see also Snell \& Grigg, 1987).

In addition to determining whether children have acquired the skills needed in the receiving program, determining whether the child can perform the skills fluently and within the range of children in that program is important. This can be accomplished through the use of discrepancy analysis (Wolery, Bailey, \& Sugal, 1988).

The steps for conducting a discrepancy analysis are: (a) identify children who are competent performers of the target behaviors in the receiving classroom, (b) identify the situations and setting where the target behaviors will be needed, (c) select a measurement system, (d) collect data on the competent performers doing the target behaviors in needed situations over 2 to 4 sessions, and (e) analyze the data by computing the mean and range for the competent performers. The performance of the child who is being prepared for transition then is compared to the mean and range of the competent performers.

Fowler (1982) recommends analyzing the differences in the sending and receiving programs to identify skills to teach the preschooler and ways to modify the sending program to prepare the child for transition. She suggests that these programs may differ in terms of classroom composition, teacher attention and reinforcement, physical arrangement, daily schedule, classroom rules and routines, academics, self-care skills, and support systems. Questions for assessing each of these potential differences are listed.

An alternative is to assess the child using developed checklists of "survival skills" in kindergarten and primary special education programs. Examples of behaviors from such checklists are shown in Table 3. Although limited evidence exists suggesting that the behaviors listed in Table 3 promote greater success in receiving programs, some of these behaviors clearly are helpful. Skills in initiating interactions, staying on task when not interacting; complying with classroom rules and routines (thereby reducing teacher management time), and performing task requirements of the classroom appear to be important for succeeding in integrated kindergarten (Walter \& Vincent, 1982).

Once a receiving program has been targeted and an assessment of the demands of that program has been completed, the team should develop and implement an individualized transition plan. This may be a part of the child's IEP, or it can be a separate document. Intervention procedures used to prepare children for the receiving program involve (a) teaching the behaviors needed in that program (Wolery, 1987; Wolery et al., 1988; Wolery, Ault, \& Doyle in press); (b) using contingencies and behavior management systems found in that program (Fowler, 1982); (c) modifying the sending classroom design and operation to match that of the receiving program (Byrd, 1987; Fowler, 1982); and (d) using procedures to facilitate maintenance and generalization of needed skills (Wolery, 1987; Wolery et al., in press). As with any instructional program, the plan should be monitored and adjusted as needed (Byrd, 1987).

Once intervention has occurred, follow-up is important (Fowler, 1982; Hanline, 1988; Diamond et al., 1988). The sending program can use follow-up information to modify its transition procedures, to identify and assist in correcting problems, to assess appropriateness of the placement, and to identify skills that should be taught to other students (Fowler, 1982; Vincent et al., 1980). Follow-up information can be collected by interviews and informal contacts with the receiving program staff members, interviews with families, and observation of the transition child.

In summary, the goals of transition procedures with children are to prepare them to function in the receiving pro- 


\section{TABLE 3}

\section{Skills on Checklists for Assessing Entry into School-Age Programs}

Source/Skill Area

Polloway (1987)

Self-related Skills

Task-Related Skills

Interpersonal Skills

Environmental Awareness

Byrd (1987)

Classroom Rules

Work Skills

Communication Skills

Social Behavior Skills

Self-Management Skills

McCormick \& Kawate (1982)

Independent Task Work

Group Attending/Participation

Follows Class Routine

Appropriate Classroom Behavior

Self-Care

Direction Following

Social/Play Skills

Functional Communication

\section{Selected Examples of Specific Skills}

Accepts consequences for own behavior

Has self care/hygiene abilities

Completes task within time allotted

Demonstrates task persistence

Shows respect for others' feelings and property

Greets others

Moves appropriately about the classroom

Locates and replaces materials

Waits quietly in line

Replaces materials, cleans up own work place

Stops activity when given direction "stop"

Completes tasks given developmentally appropriate material

Comes to adult when signaled

Attends to peers or adult who is talking to a group

Modifies behavior when provided with verbal direction

Is willing to try something new

Eats lunch or snack with minimal assistance

is aware of obvious dangers and avoids them

Stays on task without extra teacher directions

Completes task at criterion

Sits appropriately

Does not disrupt peers

Locates own possessions and returns them to appropriate locations

Makes transitions from one activity to the next with general group verbal cues

Waits appropriately

Uses time between activities appropriately

Washes hands without supervision

Takes care of own toileting needs without supervision

Complies with simple directions provided by adult to child

Follows two-step directions

Spontaneously begins play activities during play time

Interacts verbally with peers

Asks for information

States needs

Adapted from the following sources:

Polloway, E.A., 1987. Transition services for early age individuals with mild mental retardation, in R.N. lanacone \& R.A. Stodden (Eds.) Transition issues and directions (pp. 11-24). Reston, VA: Council for Exceptional Children, Division on Mental Retardation.

Byrd, R., 1987. Project STEPS: Helpful entry level skills and instructional strategies. Lexington, KY: Child Development Centers of the Bluegrass.

McCormick, L., \& Kawate, J., 1982. Kindergarten survival skills. New directions for preschool special education. Education \& Training of the Mentally Retarded, 17, 247-252. 
gram and to ensure a smooth adjustment to that program. Defining exit criteria, assessing children for developmental performance and for the skills needed in the receiving program, implementing a transition plan, and following up on the success of that plan and placement are appropriate activities.

\section{Interagency Issues and Procedures}

Developing and implementing transition procedures are seen as primary functions of early intervention program administrators (Shearer \& Mori, 1987). Communication between programs is a necessary prerequisite for smooth transitions of infants/children and families. This communication is best established through frequent, informal contacts between the relevant parties (Diamond et al., 1988). In addition to communication, the sending and receiving programs must establish coordinated transition guidelines and procedures. This involves establishing what information is needed by the receiving agency, securing the release of confidential information, identifying persons to whom information should flow, determining what assessment information is needed and can be used, scheduling the events of the transitions (e.g., assessment dates, IEP planning meetings), and negotiating difficulties that arise. To ensure smooth transitions, the procedures should be reviewed yearly, and new staff in both programs should receive orientation and training related to those procedures.

Several models exist for establishing interagency transition procedures. These include the Skidmore College Center for Child Study model (Diamond et al., 1988), the Supported Transition to Integrated Preschools model in San Francisco (Hanline \& Knowlton, 1988), and the Sequenced Transition to Education in the Public Schools (STEPS) in Lexington, Kentucky (Byrd, 1987; Weiner \& Koppelman, 1987).

\section{SUMMARY}

Transitions involve movement from one program to another. They should be studied and planned to ensure continuity of services, minimize disruptions to families, and prepare the infant/child for the next placement. Also, such planning is required, in part, by PL 99-457. Smooth transitions are accomplished by assessing and addressing the needs of infants/children and families, establishing communication between families and sending and receiving programs, including families in decision making, and ensuring information exchange and coordinated procedures between the sending and receiving programs.

\section{REFERENCES}

Bailey, D.B. (1988a). Assessing critical events. In D.B. Bailey \& R.J. Simeonsson (Eds.), Family assessment in early intervention (pp. 119-138). Columbus, $\mathrm{OH}$ : Charles Merrill.

Bailey, D.B. (1988b). Assessing family stress and needs. In D.B. Bailey \& R.J. Simeonsson (Eds.), Family assessment in early intervention (pp. 95-118). Columbus, OH: Charles Merrill.

Bailey, D.B., \& Simeonsson, R.J. (1988). Family assessment in early intervention. Columbus, $\mathrm{OH}$ : Charles Merrill.

Bailey, D.B., Simeonsson, R.J., Winton, P.J., Huntington, G.S., Comfort, M., Isbell, P., O’Donnell, K.J., \& Helm, J.M. (1986). Familyfocused intervention: A functional model for planning, implementing, and evaluating individualized family services in early intervention. Journal of the Division for Early Childhood, 10, 156-171.

Bailey, D.B., \& Wolery, M. (1984). Teaching infants and preschoolers with handicaps. Columbus, $\mathrm{OH}$ : Merrill.

Bailey, D.B., \& Wolery, M. (1989). Assessing infants and preschoolers with handicaps. Columbus, $\mathrm{OH}$ : Merrill.

Bray, N.M., Coleman, J.M., \& Bracken, M.B. (1981). Critical events in parenting handicapped children. Journal of the Division for Early Childhood, 3, 26-33.

Bronfenbrenner, U. (1986). Ecology of the family as a context for human development: Research perspectives. Developmental Psychology, $22,723-42$.

Brown, L., Branston, M.B., Hamre-Nietupski, S., Pumpian, I., Certo, N., \& Gruenwald, L.A. (1979). A strategy for developing chronological age appropriate and functional curricular content for severely handicapped adolescents and young adults. Journal of Special Education, 13, 81-90.

Byrd, R. (1987). Project STEPS: Helpful entry level skills and instructional strategies. Lexington, KY: Child Development Centers of the Bluegrass.

Carta, J.J., Sainato, D.M., \& Greenwood, C.R. (1988). Advances in the ecological assessment of classroom instruction for young children with handicaps. In S.L. Odom \& M.B. Karnes (Eds.), Early intervention for infants and children with handicaps: An empirical base (pp. 217-239). Baltimore: Paul Brookes.

Diamond, K.E., Spiegel-McGill, P., \& Hanrahan, P. (1988). Planning for school transition: An ecological-developmental approach. Journal of the Division for Early Childhood, 12, 245-252.

Dunst, C.J. (1985). Rethinking early intervention. Analysis \& Intervention in Developmental Disabilities, 5, 165-201.

Dunst, C.J., Trivette, C., \& Deal, A. (1988). Enabling and empow'ering fanilies: Principles and guidelines for practice. Cambridge, MA: Brookline Books.

Flynn, L.L., \& McCollum, J. (in press). Support systems: Strategies and implications for hospitalized newborns and families. Journal of Early Intervention.

Fowler, S.A. (1982). Transition from preschool to kindergarten for children with special needs. In K.E. Allen \& E.M. Goetz (Eds.), Early childhood education: Special problents, special solutions (pp. 309-334). Rockville, MD: Aspen.

Fowler, S.A., Chandler, L.K., Johnson, T.E., \& Stella, M.E. (1988). Individualizing family involvement in school transitions: Gathering information and choosing the next program. Journal of the Division for Early Childhood, 12, 208-216.

Goetz, E.M., Ayala, J.M., Hatfield, V.L., Marshall, A.M., \& Etzel, B.C. (1983). Training independence in preschoolers with an auditory 


\title{
Ixcellence in Educating the Gifted
}

\author{
ohn F. Feldhusen, Purdue University
}

oyce L. VanTassel-Baska, College of William

nd Mary

Cen R. Seeley, Clayton College (Denver)

\section{ROMIHD PRDPACD8:}

he highest satisfaction in life comes to those who use their bilities and talents to the fullest extent and who create new leas, inventions or works of art. Thus, this book was conived to delineate the many facets of gifted individuals nd their learming patterms, so that they may be enabled to ach their greatest potential.

$n$ expansion of an earlier, well-respected text, this book mains in the vanguard of gifted education. It offers a mprehensive introduction to the key topics, issues, and

\section{PDCH WDAURDS}

Points out major study results - Terman and Oden, the Marland Report, Leadership Training Institutes

Discusses issues and controversies, including the "pull-out" resource room model

Addresses concerns about enrichment, acceleration, individualization

Emphasizes the roles of facilitators - teachers, counselors, mentors

\section{DNPDNIST}

1 Introduction

art I The Gifted and Individual Differences

2 Characteristics and Needs of the Gifted

3 Underachieving and Handicapped Gifted Learners

4 Gifted Girls

5 Disadvantaged Gifted Learners

6 The Highly Gifted

7 Identification and Assessment of the Gifted

art II Program Development

8 Program Models for Gifted Education

9 A Comprehensive Model of Gifted Program Development

0 Evaluating Programs for Gifted Learners

1 Key Administrative Concepts in Gifted Program

Development

controversies in the field. Major topical areas include: the nature of giftedness; specific gifted subpopulations; identification processes; program development; curriculum and instruction, and facilitators (teachers, counselors, mentors).

\section{Contributors to the book are experts in the field, offering insights from both research and experiential backgrounds. Specific methods and strategies, based on strongly developed philosophical underpinnings, give practical teaching sugges- tions to help the beginning and experienced educator.

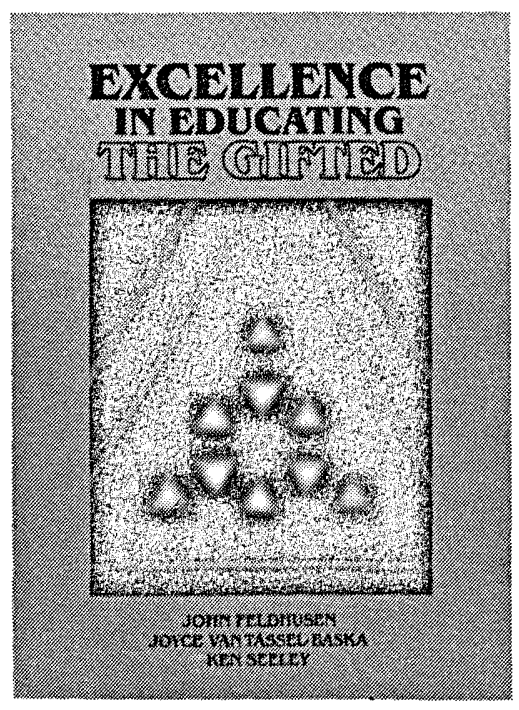 \\ Part III Curriculum and Instruction \\ 12 Appropriate Curriculum for the Gifted \\ 13 Math and Science Curriculum for the Gifted \\ 14 Social Studies and Language Arts for the Gifted \\ 15 Arts and Humanities for the Gifted \\ 16 Thinking Skills for the Gifted \\ 17 Instructional Methods for the Gifted \\ Part IV Helping the Gifted Achieve Excellence \\ 18 Facilitators for Gifted Learners \\ 19 Counseling the Gifted \\ 20 Synthesis \\ 8901/hardbound/ISBN 0-89108-205-0 \\ $\$ 29.95$}

. 
stimulus management technique. Education \& Treatment of Children, 6, 251-261.

Hains, A.H., Fowler, S.A., \& Chandler, L.K. (1988). Planning school transitions: Family and professional collaboration. Journal of the Division for Early Childhood, 12, 108-115.

Hanline, M.F. (1988). Making the transition to preschool: Identification of parent needs. Journal of the Division for Early Childhood, 12, 98-107.

Hanline, M.F., \& Knowlton, A. (1988). A collaborative model for providing support to parents during their child's transition from infant intervention to preschool special education public school programs. Journal of the Division for Early Childhood, 12, 116-125.

Harrison, H. (1983). The premature baby book: A parents' guide to coping and caring in the first years. New York: St. Martin's Press.

Howell, L.J. (1988). Home ostomy care. In R.A. Ballard (Ed.), Pediatric care of the ICN graduate (pp. 306-316). Philadelphia: W.B. Saunders.

Hutinger, P.L. (1981). Transition practices for handicapped young children: What the experts say. Journal of the Division for Early Childhood, 2, 8-14.

Iancone, R.N., \& Stodden, R.A. (1987). Transition issues and directions. Reston, VA: Council for Exceptional Children, Division on Mental Retardation.

Johnson, T.E., Chandler, L.K., Kerns, G.M., \& Fowler, S.A. (1986). What are parents saying about family involvement in school transitions? A retrospective transition interview. Journal of the Division for Early Childhood, 11, 10-17.

Katz, K.S., Pokorni, J.L., \& Long, T.M. (1988). Project CIII: Chronically ill infant intervention project, contimuity in intervention from hospital to home. Washington, DC: Georgetown University, Child Development Center.

Lang, M.D., Behle, M.B., \& Ballard, R.A. (1988). The transition from hospital to home. In R.A. Ballard (Ed.), Pediatric care of the ICN graduate (pp. 12-16). Philadelphia, PA: W.B. Saunders.

MacKeith, R. (1973). The feelings and behavior of parents of handicapped children. Developmental Medicine and Child Neurology, 15 524-527.

Noonan, M.J., \& Kilgo, J.L. (1987). Transition services for early age individuals with severe mental retardation. In R.N. Ianacone \& R.A Stodden (Eds.), Transition issues and directions (pp. 25-37). Reston, VA: Council for Exceptional Children, Division on Mental Retardation.

Noonan, M.J., \& Stodden, R.A. (1986). The preschool preparation and transition model: Preparing handicapped infants for least restrictive preschool environments. (Technical Proposal, U.S. Office of Special Education Project No. 024RH60073). Honolulu: University of Hawaii, Dept. of Special Education.

Platzker, A.C.G., Lew, C.D., Cohen, S.R., Thompson, J., Ward, S.L.D., \& Keens, T.G. (1988). Home care of infants with chronic lung disease. In R.A. Ballard (Ed.), Pediatric care of the ICN graduate (pp. 289-294). Philadelphia: W.B. Saunders.

Pueschel, S.M. (1988). The young person with Down syndrome: Transition from adolescent to adulthood. Baltimore: Paul Brookes.

Sainato, D.M., Strain, P.S., Lefebvre, D., \& Rapp, N. (1987). Facilitating transition times with handicapped preschool children: A comparison between peer-mediated and antecedent prompt procedures. Journal of Applied Behavior Analysis, 20, 285-291.

Seligman, M., \& Darling, B.R. (1989). Ordinary families, special children: A systems approach to childhood disability. New York: Guilford Press.
Shearer, M.S., \& Mori, A.A. (1987). Administration of preschool special education programs: Strategies for effectiveness. Journal of the Division for Early Childhood, 11, 161-170.

Simeonsson, R.J. (1988a). Assessing family environments. In D.B. Bailey and R.J. Simeonsson (Eds.), Family assessment in early intervention (pp. 167-1183). Columbus, OH: Charles Merrill.

Simeonsson, R.J. (1988b). Unique characteristics of families with young handicapped children. In D.B. Bailey \& R.J. Simeonsson (Eds.), Family assessment in early intervention (pp. 27-43). Columbus, $\mathrm{OH}:$ Charles Merrill.

Snell, M.E., \& Grigg, N.C. (1987). Instructional assessment and curriculum development. In M.E. Snell (Ed.) Systematic instruction of persons with severe handicaps (3rd ed.) (pp. 64-109). Columbus, $\mathrm{OH}$ : Charles Merrill.

Thurlow, M.L., Lehr, C.A., \& Ysseldyke, J.E. (1987). Exit criteria in early childhood programs for handicapped children. Journal of the Division for Early Childhood, 11, 118-123.

Thurlow, M.L., Ysseldyke, J.E., \& Weiss, J.A. (1988). Early childhood special education exit decisions: How are they made? How are they evaluated? Journal of the Division for Early Childhood, 12, 253-262.

Vincent, L.J., Salisbury, C., Walter, G., Brown, P., Gruenwald, L.J., \& Powers, M. (1980). Program evaluation and curriculum development in early childhood special education: Criteria of the next environment. In W. Sailor, B. Wilcox, \& L. Brown (Eds.), Methods of instruction for severely handicapped students (pp. 303-328). Baltimore: Paul Brookes.

Walter, G., \& Vincent, L. (1982). The handicapped child in the regular kindergarten classroom. Journal of the Division for Early Childhood, 6, 84-95.

Webster's Ninth New Collegiate Dictionary. (1988). Springfield, MA: Merriam-Webster.

Weiner, R., \& Koppelman, J. (1987). From birth to five: Serving the youngest handicapped children. Alexandria, VA: Capitol Publications.

Wickler, L. (1981). Chronic stresses of families of mentally retarded children. Family Relations, 30, 281-288.

Will, M. (1984). OSERS programming for the transition of youth with disabilities: Bridges from school to working life. Washington, DC: U.S. Department of Education, Office of Special Education \& Rehabilitative Services.

Winton, P.J. (1988). Effective communication between parents and professionals. In D.B. Bailey \& R.J. Simeonsson (Eds.), Family assessment in early intervention (pp. 207-228). Columbus, $\mathrm{OH}$ : Charles Merrill.

Winton, P.J., Tumbull, A.P., \& Blacher, J. (1984). Selecting a preschool: A guide for parents of handicapped children. Austin, TX: Pro-Ed.

Wolery, M. (1987). Overview of instructional issues. In R. Byrd (Ed.), Project STEPS: Helpful entry level skills and instructional strategies. Lexington, KY: Child Development Centers of the Bluegrass.

Wolery, M., Ault, M.J., \& Doyle, P.M. (in press). Teaching students with moderate and severe handicaps: Use of response prompting procedures. White Plains, NY: Longman.

Wolery, M., Bailey, D.B., \& Sugal, G.M. (1988). Effective teaching: Principles and procedures of applied behavior analysis with exceptional students. Boston: Allyn \& Bacon.

Wolery, M., Doyle, P.M., Gast, D.L., Ault, M.J., \& Lichtenberg, S. (1989). Comparison of progressive time delay and transition-based teaching with preschoolers who display developmental delays. Manuscript submitted for publication. (Department of Special Edu- 